\title{
ROCK1 promotes migration and invasion of non-small-cell lung cancer cells through the PTEN/PI3K/FAK pathway
}

\author{
CHANGPENG HU*, HUYUE ZHOU*, YALI LIU, JINGBIN HUANG, WUYI LIU, QIAN ZHANG, \\ QIN TANG, FANGFANG SHENG, GUOBING LI and RONG ZHANG
}

Department of Pharmacy, The Second Affiliated Hospital, Army Medical University, Chongqing 400037, P.R. China

Received March 28, 2019; Accepted August 13, 2019

DOI: 10.3892/ijo.2019.4864

\begin{abstract}
Rho-associated protein kinase 1 (ROCK1), a member of the ROCK family, serves an important function in cell migration and invasion in neoplasms. ROCK1 has been found to be overexpressed in several types of cancers. However, the role of ROCK1 in non-small-cell lung cancer (NSCLC) is poorly understood. In the present study, ROCK1 was found to be overexpressed in NSCLC cells and tissues, and it was associated with poor survival of NSCLC patients. Subsequently, ROCK1 knockdown NSCLC cell lines were established using shRNA. ROCK1 knockdown significantly reduced the migration and invasion ability in the cell monolayer scratching and Transwell assays. ROCK1 knockdown was also found to markedly inhibit cell adhesion ability. Moreover, the phosphorylation of focal adhesion kinase (FAK) was inhibited by ROCK1 knockdown, reducing NSCLC cell migration and invasion ability. This mechanistic study revealed that ROCK1 significantly enhanced cell migration and invasion by inhibiting the phosphatase and tensin homolog (PTEN)/phosphoinositide 3-kinase (PI3K)/FAK pathway. More importantly, the interruption of the PTEN/PI3K/FAK pathway markedly rescued the inhibition of cell migration and invasion mediated by ROCK1 knockdown. Taken together, these results suggest a novel role for ROCK1 in cell migration and invasion by inhibiting cell adhesion ability, and indicate that ROCK1 may be of value as a therapeutic target for the treatment of NSCLC.
\end{abstract}

\section{Introduction}

Lung cancer is a leading cause of cancer-related mortality worldwide $(1,2)$. Lung cancer is generally subdivided into

Correspondence to: Professor Rong Zhang or Dr Guobing Li, Department of Pharmacy, The Second Affiliated Hospital, Army Medical University, 83 Xinqiao Road, Chongqing 400037, P.R. China E-mail: xqpharmacylab@126.com

E-mail:rgwlsb@126.com

*Contributed equally

Key words: non-small-cell-lung cancer, Rho-associated protein kinase 1, phosphatase and tensin homolog, migration, invasion non-small-cell lung cancer (NSCLC) and small-cell carcinoma (SCLC) (3). The majority (60-80\%) of NSCLC patients have advanced or metastatic disease at diagnosis (4). Despite the progress in the treatment and prevention of NSCLC, its prognosis is poor. Surgical resection is a radical treatment, but its success rate is poor for metastatic tumors (5). Lung cancer constitutes a major public health concern, and further study of the molecular mechanisms underlying the migration and invasion of NSCLC may provide novel insights into NSCLC treatment.

Rho-associated protein kinase (ROCK), which consists of ROCK1 and ROCK2, is involved in regulating the movement of cells by acting on the cytoskeleton $(6,7)$. It was recently reported that ROCK1 plays a key role in regulating cell motility, angiogenesis and migration (8). In addition, ROCK1 has been reported to be overexpressed in several solid tumors, including glioblastoma (9), melanoma (10), osteosarcoma (11) and hepatocellular carcinoma (12). According to published reports, overexpression of ROCK1 has been commonly associated with more highly metastatic and invasive phenotypes in human cancers. ROCK1 was also found to phosphorylate regulatory myosin light chains (MLCs) and facilitate actin-myosin contractility (13). In addition, it was reported that ROCK1 modulates cell motility via integrin $\beta 1$-activated FAK signaling (14).

Previous studies demonstrated that focal adhesion kinase (FAK), a key regulator of cell adhesion and migration, is overexpressed in several diverse cancers, including lung cancer and multiple myeloma $(15,16)$. Activation/phosphorylation of FAK was reported in epithelial and endothelial cells during the wound healing process, suggesting that cell migration was regulated by FAK (17). In addition, the ROCK inhibitor reduced the activation of FAK, which is known to be involved in cell adhesion (18). Furthermore, connexin 43 was reported to exert a prominent antitumor effect on migration and invasion of glioblastoma cells by targeting phosphatase and tensin homolog (PTEN) and FAK (19). In addition, the PTEN/phosphoinositide 3-kinase $(\mathrm{PI} 3 \mathrm{~K}) /$ nuclear factor- $\mathrm{\kappa} \mathrm{B} / \mathrm{FAK}$ pathway was reported to be a novel mechanism involved in gastric cancer growth and invasion (20).

PTEN is a tumor suppressor that inhibits cell migration and proliferation $(21,22)$. Phosphorylation of PTEN by ROCK was shown to stimulate its phosphatase activity $(23,24)$. PTEN has been reported to weaken the tyrosine phosphorylation 
of FAK (21). In addition, PTEN may negatively regulate the PI3K/AKT pathway, which plays an important role in several biological processes $(25,26)$. However, the mechanism through which ROCK1 regulates the phosphorylation status of $\mathrm{PTEN} / \mathrm{PI} 3 \mathrm{~K} / \mathrm{AKT}$ and its role in the regulation of migration and invasion of human lung cancer cells remain elusive.

The present study was designed to investigate the role of ROCK1 in NSCLC cell migration and invasion and examine the correlation between ROCK1 expression in clinical NSCLC tissues and prognosis. ROCK1 knockdown NSCLC cell lines were established using shRNA and adhesion and migration abilities were compared. Cell monolayer scratching Transwell assays were also used to determine the effect of ROCK1 knockdown on cell migration and invasion. The aim was to determine whether ROCK1 is a potential therapeutic target and an effective predictive biomarker for NSCLC patients.

\section{Materials and methods}

Tissues. The data analysis was performed in accordance with protocols approved by the Ethics Committee of the Institutional Review Board of the Army Medical University, and all specimens were collected after obtaining written informed consent from all the patients. Samples of human lung tumor tissues and paired adjacent normal tissues were collected from 30 patients with lung adenocarcinoma at the Southwest Hospital (Chongqing, China) between June 2011 and June 2013. A series of data were recorded as follows: Patient sex, age, tumor size, clinical stage, and lymph node metastasis. The pathological diagnosis was performed according to the criteria set by the American Joint Committee on Cancer (27).

Cell culture. WI-38, NCI-H1299, A549, NCI-H226 and SK-MES-1 cells were purchased from the American Type Culture Collection and cultured in Dulbecco's modified Eagle's medium (DMEM; Thermo Fisher Scientific, Inc.) supplemented with $10 \%$ fetal bovine serum (FBS; Lonsera) and $100 \mathrm{U} / \mathrm{ml}$ penicillin/streptomycin in an atmosphere with $5 \% \mathrm{CO}_{2}$ at $37^{\circ} \mathrm{C}$. Cells were digested and passaged every 2 days.

Plasmids and establishment of stable cell lines. The human ROCK1 shRNA (5'-CCGGGCACCAGTTGTACCCGATTT ACTCGAGTAAATCGGGTACAATCTGGTGCTTTTTG-3') and control shRNA plasmid (sc-108060) were purchased from Santa Cruz Biotechnology, Inc. The human PTEN shRNA (5'-CCGGCCACAAATGAAGGGATATAAACT CGAGTTTATATCCCTTCATTTGTGGTTTTT-3') was a gift from Professor Todd Waldman (plasmid no. 25639, Addgene Inc.; http://n2t.net/addgene:25639). For gene silencing, the plasmids were cotransfected with lentiviral packaging vectors (pLP1, pLP2 and VSVG) (K4975, Invitrogen; Thermo Fisher Scientific, Inc.) into actively growing 293FT cells via Lipofectamine 3000 (L3000015, Invitrogen; Thermo Fisher Scientific, Inc.). After the 48-h transfection, lentivirus was collected from the supernatant and used to infect target cells (A549 and NCI-H1299 cells). Stable cell lines were selected by $5 \mu \mathrm{g} / \mathrm{ml}$ puromycin (P9620, Sigma-Aldrich; Merck KGaA).
Immunohistochemistry (IHC). A tissue microarray containing samples from 30 lung adenocarcinoma patients was subjected to IHC staining to detect ROCK1 expression. IHC was implemented as the standard procedure. An anti-ROCK1 antibody $(1: 1,000 ;$ rabbit; ab45171; Abcam) was used. The expression of ROCK1 was evaluated according to the immunoreactive score (IRS) described by Remmele and Stegner (28). In brief, 0, 1, 2, 3 or 4 was used to describe $0,1-25,26-50,51-75$, and 76-100\% positive cells, respectively. In addition, $0,1,2$ or 3 were assigned to negative, weak, moderate and strong staining intensity of positive cells, respectively. The IRS was indicated as the arithmetic product of the positive cell proportion and the staining intensity. The range of IRS was 1-12 (29,30).

Analysis of microarray data. The Oncomine cancer microarray database (http://www.oncomine.org) was used to study the expression of ROCK1 in NSCLC samples (GSE19188). Gene expression data were obtained from the NCBI Gene Expression Omnibus (GEO) database (accession nos.: GSE19188, GSE30219 and GSE3141). ROCK1 expression data were log-transformed and median-centered per array, and the standard deviation was normalized to one per array. Patient data and gene expression datasets were obtained from the R2 microarray analysis and visualization platform (http://hgserverl.amc.nl). All prognosis analyses were performed online, and all the data and P-values (log-rank test) were downloaded. The univariate survival analysis within the NSCLC dataset of GSE19188, GSE30219 and GSE3141 was performed using the Kaplan-Meier analysis module of the R2 microarray analysis and visualization platform.

Western blotting. Prepared cells were extracted and lysed with RIPA lysis buffer (P0013B, Beyotime Biotechnology) supplemented with PMSF (1 mM). Proteins were then treated with the Enhanced BCA Protein Assay Reagent (P0009, Beyotime Biotechnology) prior to quantifying the protein concentration by a microplate reader. Subsequently, equal amounts of total protein $(15-60 \mu \mathrm{g})$ were separated by $10 \%$ SDS-PAGE and transferred to PVDF membranes (162-0177, Bio-Rad Laboratories, Inc.). The membranes were blocked with 5\% bovine serum albumin at room temperature for $2 \mathrm{~h}$, and then incubated with primary antibodies overnight at $4^{\circ} \mathrm{C}$. The following antibodies were used: Anti-PTEN (1:500; mouse; sc-7974; Santa Cruz Biotechnology, Inc.), anti-GAPDH (1:2,000; mouse; sc-47724; Santa Cruz Biotechnology, Inc.), anti-p-FAK (1:1,000; rabbit; 381143; ZENBIO), anti-p-FAK (1:1,000; rabbit; 3283s; Cell Signaling Technology, Inc.), anti-FAK (1:1,000; rabbit; 3285s; Cell Signaling Technology, Inc.), anti-p-PTEN (1:1,000; rabbit; 9554s; Cell Signaling Technology, Inc.), anti-p-PI3K (1:500; rabbit; 4228s; Cell Signaling Technology, Inc.), anti-PI3K (1:1,000; rabbit; 4257s; Cell Signaling Technology, Inc.), anti-p-AKT (1:1,000; rabbit; 4060s; Cell Signaling Technology, Inc.), anti-AKT (1:500; rabbit; 9272s; Cell Signaling Technology, Inc.), anti-ROCK1 (1:1,000; rabbit; ab45171; Abcam) and anti-actin (1:10,000; mouse; 1978; Sigma-Aldrich; Merck KGaA). After washing with TBST three times, the membranes were incubated with the appropriate secondary antibody $(1: 5,000)$ for $2 \mathrm{~h}$ at room temperature and bands were observed by an enhanced chemiluminescence kit (170-5061, Bio-Rad Laboratories, 
Inc.). Densitometric analysis was performed by Quantity One software (Bio-Rad Laboratories, Inc.). The results represent three independent experiments.

Immunofluorescence. The cells were counted and cultured in 24-well plates with glass coverslips. When the cells reached $\sim 70 \%$ confluency, they were fixed with Immunol Staining Fix Solution (Beyotime Biotechnology) for $15 \mathrm{~min}$, permeated with $0.1 \%$ Triton X-100 in PBS for 5 min and blocked with $5 \%$ non-fat dry milk in PBS for 30 min. Subsequently, the cells were incubated with Alexa Fluor 555 Phalloidin (8953s, Cell Signaling Technology, Inc.) for $30 \mathrm{~min}$. After washing in PBS, the cells were incubated with anti-p-FAK (381143, rabbit, ZENBIO, 1:50) overnight at $4^{\circ} \mathrm{C}$. The cells were treated with Alexa Fluor 488 anti-rabbit secondary antibody (Santa Cruz Biotechnology, Inc.) for $1 \mathrm{~h}$ in the dark and then counterstained with DAPI (Sigma-Aldrich; Merck KGaA) for 5 min. Finally, the fluorescence of the labeled cells was visualized by a laser-scanning confocal microscope (LSM780NLO, Zeiss $\mathrm{GmbH})$.

Cell monolayer scratching assay. The cells were grown in 6-well plates with DMEM supplemented with 10\% FBS until the formation of a $\sim 95 \%$ confluent monolayer. A 1-ml pipette tip was used to scratch the bottom of the plates in a straight line. After washing with PBS, the wounds were monitored at 0 and $48 \mathrm{~h}$ using the Cell Imaging System (Zeiss $\mathrm{GmbH}$ ). The migration capacity of the cells was measured as cells covered the wounds at $48 \mathrm{~h}$ compared with $0 \mathrm{~h}$. The results represent three independent experiments.

Transwell assay. The lower chambers of a Transwell insert (3422, Corning, Inc.) were filled with DMEM supplemented with $30 \%$ FBS. A total of 5,000 cells in serum-free DMEM were seeded in the upper chambers. After a 48-h incubation, the membranes were fixed with $4 \%$ formaldehyde for $15 \mathrm{~min}$. The cells remaining on the upper surface of the membrane were carefully wiped with cotton swabs, and the cells that migrated to the bottom of the filter were stained with a $1 \%$ crystal violet solution (Beyotime Biotechnology). Each well was then filled with PBS and examined under a microscope (CKX41, Olympus Corporation). The number of invading cells was counted in three randomly selected fields.

Cell adhesion assays. In the attachment assays, the cells were counted and plated into a 12 -well plate $\left(5 \times 10^{3}\right.$ per well $)$ and incubated for 10-180 min. At each time point, the non-adherent cells were discarded. The adherent cells were gently washed with PBS, trypsinized and counted. In the detachment assays, $1 \mathrm{ml}$ of cells $\left(1 \times 10^{3}\right.$ cells $\left./ \mathrm{ml}\right)$ was added to each well of a 12-well plate and incubated for $24 \mathrm{~h}$. Then, each well was trypsinized (1 $\mathrm{ml}$ trypsin was diluted in $19 \mathrm{ml}$ PBS) for varying lengths of time (20-180 sec). The non-adherent cells suspended in media were aspirated, and each well was washed gently with PBS. The remaining adherent cells were digested and counted. Each experiment was repeated three times individually.

Statistical analysis. The data are presented as the mean \pm standard deviation. The statistical analysis was performed using GraphPad Prism version 6.0 (GraphPad Software, Inc.).
Chi-squared tests were performed to evaluate the significance of the associations between ROCK1 and clinicopathological parameters. The statistical evaluation was performed by Student's t-test. One-way ANOVA was used for multiple comparisons followed by the Bonferroni method. The results were considered statistically significant at ${ }^{*} \mathrm{P}<0.05,{ }^{* *} \mathrm{P}<0.01$ and ${ }^{* * *} \mathrm{P}<0.001$.

\section{Results}

High ROCK1 expression predicts poor survival in NSCLC patients. To investigate the role of ROCK1 in the development of NSCLC, we examined the expression of ROCK1 in NSCLC. First, the levels of ROCK1 were measured in NSCLC tissues from 30 patients and adjacent normal tissues by IHC. The results demonstrated that the expression of ROCK 1 in NSCLC was significantly higher compared with that in adjacent normal tissues $\left({ }^{* *} \mathrm{P}=0.0035\right.$, Fig. $1 \mathrm{~A}$ and B). Subsequently, the correlation between ROCK1 expression and different clinicopathological factors in NSCLC was analyzed. The results revealed that the expression of ROCK1 was significant positively correlated with tumor size $\left({ }^{* *} \mathrm{P}=0.0038\right)$, lymph node metastasis $\left({ }^{* *} \mathrm{P}=0.0012\right)$ and clinical stage $\left({ }^{* * *} \mathrm{P}=1.17 \mathrm{E}-05\right)$ (Table I). Moreover, the expression of ROCK1 mRNA in NSCLC was evaluated using the publicly available Oncomine database (www.oncomine.org). The NSCLC microarray expression dataset was analyzed, and the results demonstrated that the expression of ROCK1 mRNA was significantly higher in NSCLC compared with that in non-tumor tissues in the microarray study. The fold increase in ROCK1 mRNA levels in lung adenocarcinoma and large-cell lung carcinoma were 1.158 and 1.179 , respectively, in a microarray dataset (GSE19188) (Fig. 1C and D). The Kaplan-Meier analysis from the R2 microarray analysis and visualization platform (http://r2.amc.nl) indicated that NSCLC patients with high ROCK1 expression had worse survival compared with those with lower ROCK1 expression in three datasets (GSE19188, GSE30219 and GSE3141) (Fig. 1E-G). Subsequently, the ROCK1 expression levels were measured in several NSCLC cell lines (NCI-H1299, A549, NCI-H226 and SK-MES-1) and WI38 human embryonic lung fibroblasts. ROCK1 was found to be highly expressed in the abovementioned NSCLC cell lines compared with its levels in WI38 cells $\left({ }^{* *} \mathrm{P}<0.01\right.$ and ${ }^{*} \mathrm{P}<0.05$, Fig. $1 \mathrm{H}$ and I). Collectively, these data indicate that a higher ROCK1 expression level predicts worse survival in NSCLC. In addition, monitoring ROCK1 expression may provide new prognostic, diagnostic and therapeutic strategies for NSCLC treatment.

ROCK1 promotes cell migration and invasion. Subsequently, to further investigate the functional effect of ROCK1 on cell migration and invasion in NSCLC, ROCK1 was knocked down in A549 and NCI-H1299 NSCLC cells by shRNA, and the results are shown in Fig. 2A. The scratch migration assay demonstrated that ROCK1 knockdown decreased wound closure in A549 and NCI-H1299 cells ( ${ }^{* *} \mathrm{P}<0.01$, Fig. 2B and C), indicating that ROCK1 knockdown inhibited cell migration. The Transwell assay also revealed that ROCK1 knockdown inhibited A549 and NCI-H1299 cell invasion $\left(^{* *} \mathrm{P}<0.01\right.$, Fig. 2D and E). In addition, the effects of ROCK1 on NSCLC 
A

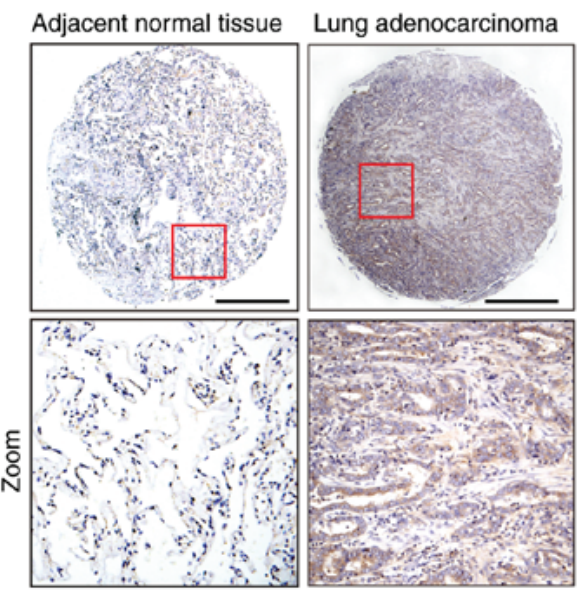

C

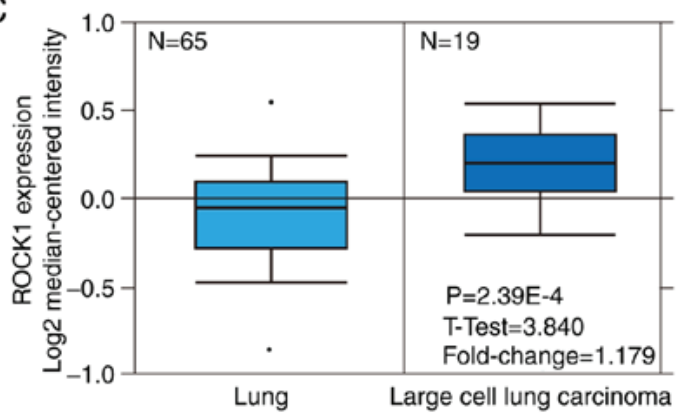

B

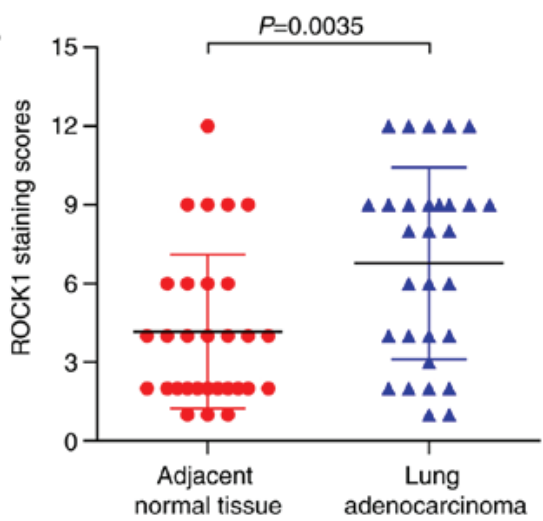

D

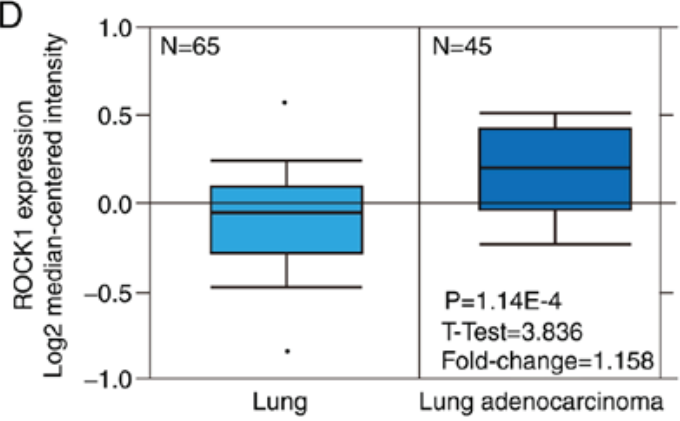

E

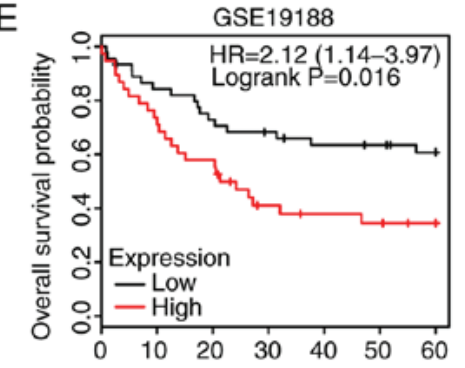

Number at risk Time (months)

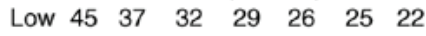

$\begin{array}{lllllll}\text { High } 38 & 28 & 22 & 13 & 11 & 10 & 8\end{array}$
$\mathrm{F}$

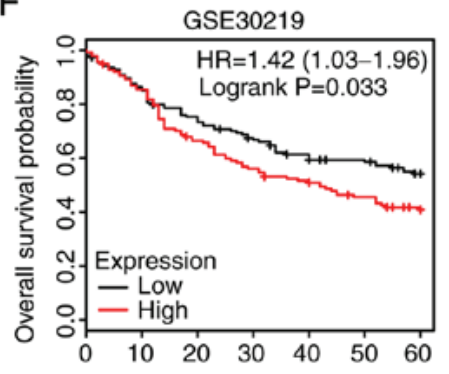

Number at risk Time (months)

Low $\begin{array}{lllllll}155 & 133 & 115 & 101 & 90 & 83 & 71\end{array}$

High $\begin{array}{lllllll}138 & 117 & 90 & 76 & 69 & 59 & 50\end{array}$
G

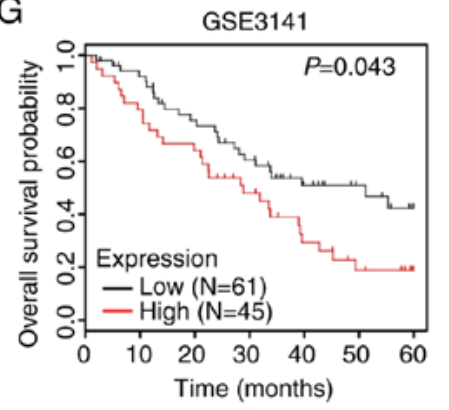

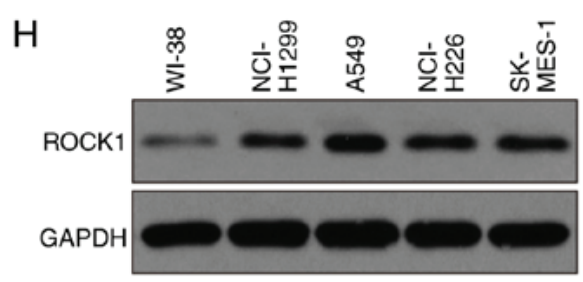

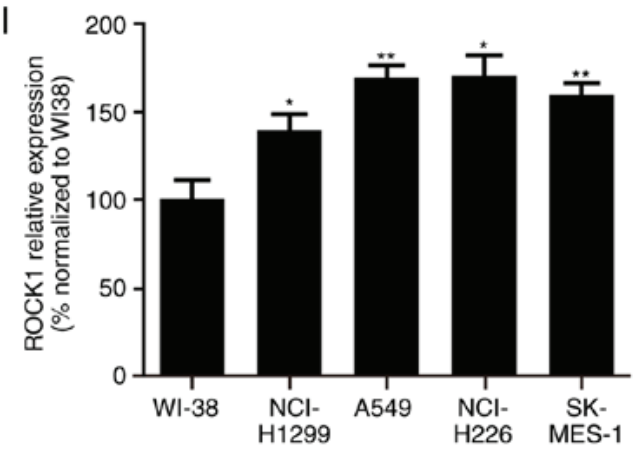

Figure 1. ROCK1 is overexpressed in NSCLC, and higher expression of ROCK1 predicts worse survival. The expression of ROCK1 was measured in lung adenocarcinoma tissues and cells. (A) Representative immunohistochemical images of ROCK1 in lung adenocarcinoma and adjacent normal tissues. Scale bars: $100 \mu \mathrm{m}$. (B) Expression level of ROCK1 in lung adenocarcinoma and adjacent normal tissues $\left(\mathrm{n}=30,{ }^{* *} \mathrm{P}=0.0035\right)$. (C and D) The expression of ROCK1 is upregulated in NSCLC tissues compared with non-tumor tissues. All the data (fold change and P-values) were calculated from Oncomine (www.oncomine. org). (E-G) The survival analysis was performed by the Kaplan-Meier method in the GSE19188 ( $\left.\mathrm{n}=83,{ }^{*} \mathrm{P}=0.016\right)$, GSE30219 ( $\mathrm{n}=293$, $\left.{ }^{*} \mathrm{P}=0.033\right)$ and GSE3141 datasets $\left(\mathrm{n}=106,{ }^{*} \mathrm{P}=0.043\right)$. (H-I) The expression level of ROCK1 was detected by western blotting in NSCLC cell lines (NCI-H1299, A549, NCI-H226 and SK-MES-1) and human embryonic lung fibroblasts WI38. The relative densities of ROCK1 were normalized to GAPDH by densitometric analysis using Quantity One software $\left({ }^{*} \mathrm{P}<0.05,{ }^{* *} \mathrm{P}<0.01\right.$, vs. the WI-38 group). The results represent three independent experiments. ROCK1, Rho-associated protein kinase 1; NSCLC, non-small-cell lung cancer. 
Table I. Correlation between ROCK1 expression and clinicopathological factors of lung cancer patients.

\begin{tabular}{lccc}
\hline Clinicopathological & $\begin{array}{c}\text { High ROCK1 } \\
\text { expression } \\
\text { factors }\end{array}$ & $\begin{array}{c}\text { Low ROCK1 } \\
\text { expression } \\
(\mathrm{n}=11)\end{array}$ & P-value \\
\hline Sex & 8 & 3 & $0.0470^{\mathrm{a}}$ \\
$\quad$ Male & 11 & 8 & \\
Female & & & 0.5769 \\
Age, years & 10 & 6 & \\
$\geq 60$ & 9 & 5 & \\
$<60$ & & & $0.0038^{\mathrm{b}}$ \\
Tumor size, cm & 13 & 6 & \\
$\geq 3$ & 6 & 5 & $1.17 \mathrm{E}-05^{\mathrm{c}}$ \\
$<3$ & & & \\
Clinical stage & 0 & 5 & $0.0012^{\mathrm{b}}$ \\
I & 19 & 6 & \\
II-III & & & \\
Lymph node & & 4 & \\
metastasis & & & \\
Yes & 6 & & \\
No & & & \\
\hline
\end{tabular}

${ }^{\mathrm{a}} \mathrm{P}<0.05,{ }^{\mathrm{b}} \mathrm{P}<0.01,{ }^{\mathrm{c}} \mathrm{P}<0.001$. ROCK1, Rho-associated protein kinase 1.

cell adhesion were investigated. The cellular attachment and detachment rates in control and ROCK1 knockdown cell lines were measured on fibronectin-coated surfaces. ROCK1 knockdown cells displayed slower attachment compared with control cells $\left({ }^{* *} \mathrm{P}<0.01\right.$ and ${ }^{*} \mathrm{P}<0.05$, Fig. $2 \mathrm{~F}$ and $\left.\mathrm{G}\right)$. Consistent with previous results, ROCK1 knockdown significantly decreased the cell detachment rates after trypsinization compared with that in control cells $\left({ }^{* * *} \mathrm{P}<0.001\right.$, Fig. $2 \mathrm{H}$ and I). These results suggest that ROCK1 knockdown decreased A549 and NCI-H1299 cell adhesion. Taken together, these results suggest that ROCK1 knockdown not only decreases the migratory and invasive abilities, but also suppresses the adhesive ability of NSCLC cells.

ROCK1-mediated lamellipodia formation is dependent on FAK activation. It has been reported that FAK, an adhesion-associated protein, plays an important role in cancer cell migration and invasion (31,32). We next investigated whether ROCK1 knockdown affected the expression of FAK. The western blot analysis demonstrated that ROCK1 knockdown significantly decreased the phosphorylation of FAK (activated form), while the expression level of FAK was not affected by ROCK1 ${ }^{* * *} \mathrm{P}<0.001$, Fig. 3A and B). Furthermore, an immunofluorescence assay was performed to determine whether ROCK1 knockdown could affect the subcellular localization of FAK. The results demonstrated that ROCK1 knockdown significantly reduced the colocalization of p-FAK with actin in A549 and NCI-H1299 cells (Fig. 3C), which is characteristic of lamellipodia (33), suggesting that ROCK1 knockdown inhibited lamellipodia formation in NSCLC cells. Taken together, these findings support that ROCK1 affects migration and invasion of NSCLC cells through inhibiting lamellipodia formation via dephosphorylation/inactivation of FAK.

ROCK1 promotes cell migration and invasion via PI3K pathway targeting FAK in NSCLC. Recent studies have reported that FAK is involved in regulating migration and invasion through the PI3K pathway $(34,35)$. We next examined the effects of ROCK1 on the expression and activation of PI3K. As shown in Fig. 4A, ROCK1 knockdown resulted in a significant decrease of $\mathrm{p}-\mathrm{PI} 3 \mathrm{~K}\left({ }^{* * *} \mathrm{P}<0.001\right)$; however, there was no significant difference in the expression of PI3K (Fig. 4A and B). To further confirm the role of the PI3K pathway in ROCK1-mediated migration and invasion, a specific PI3K inhibitor, LY294002, was used. Pretreatment with LY294002 further reduced the dephosphorylation of AKT (an important substrate of PI3K) mediated by ROCK1 knockdown $\left({ }^{* * *} \mathrm{P}<0.001\right.$, Fig. $4 \mathrm{C}$ and $\left.\mathrm{D}\right)$. In addition, pretreatment with LY294002 also significantly decreased the ROCK1 knockdown-mediated dephosphorylation of FAK $\left({ }^{* *} \mathrm{P}<0.01\right.$ and ${ }^{* * *} \mathrm{P}<0.001$, Fig. $4 \mathrm{C}$ and $\left.\mathrm{D}\right)$. Furthermore, the Transwell and scratch migration assays demonstrated that pretreatment with LY294002 significantly enhanced the inhibition of cell invasion and wound closure mediated by ROCK1 knockdown $\left({ }^{* *} \mathrm{P}<0.01\right.$ and ${ }^{* * *} \mathrm{P}<0.001$, Fig. 4E-H). Taken together, these findings indicate that the PI3K/FAK pathway is involved in ROCK1-mediated cell migration and invasion in NSCLC.

ROCK1 regulates PTEN-dependent migration and invasion through the PI3K/FAK pathway. PTEN is a negative regulator of the PI3K/AKT pathway, and ROCK1 plays a key role in the control of PTEN activation (26,35-37). The present study first examined the effects of ROCK1 knockdown on PTEN activation, and found that ROCK1 knockdown significantly increased the level of p-PTEN (the activated form of PTEN), but did not affect the expression of PTEN (Fig. 4A). PTEN was further knocked down by shRNA to confirm its pivotal role in ROCK1-mediated cell migration and invasion (Fig. 5A). The results of the western blot assay indicated that knocking down PTEN also caused a downregulation of p-PTEN and reversed ROCK1 knockdown-induced p-PTEN activation in both A549 and NCI-H1299 cells ( ${ }^{* * *} \mathrm{P}<0.001$, Fig. 5B and C). PTEN knockdown also significantly increased the expression of p-PI3K and p-FAK, and blocked further reduction of $\mathrm{p}-\mathrm{PI} 3 \mathrm{~K}$ and $\mathrm{p}-\mathrm{FAK}$ mediated by the ROCK1 knockdown $\left({ }^{* *} \mathrm{P}<0.01\right.$ and ${ }^{* * *} \mathrm{P}<0.001$, Fig. 5B, D and E). Furthermore, the Transwell and scratch migration assays demonstrated that PTEN knockdown promoted invasion and wound closure in A549 and NCI-H1299 cells, and PTEN knockdown also reversed ROCK1 knockdown-mediated inhibition of cell invasion and wound closure $\left({ }^{* *} \mathrm{P}<0.01\right.$ and ${ }^{* * *} \mathrm{P}<0.001$, Fig. 5F-I). Taken together, these findings suggest that PTEN plays a crucial role in ROCK1-regulated PI3K/FAK pathway activation and subsequent cell migration and invasion.

\section{Discussion}

Tumor metastasis indicates aggressiveness and poor prognosis in NSCLC. It is crucial to investigate the mechanisms 

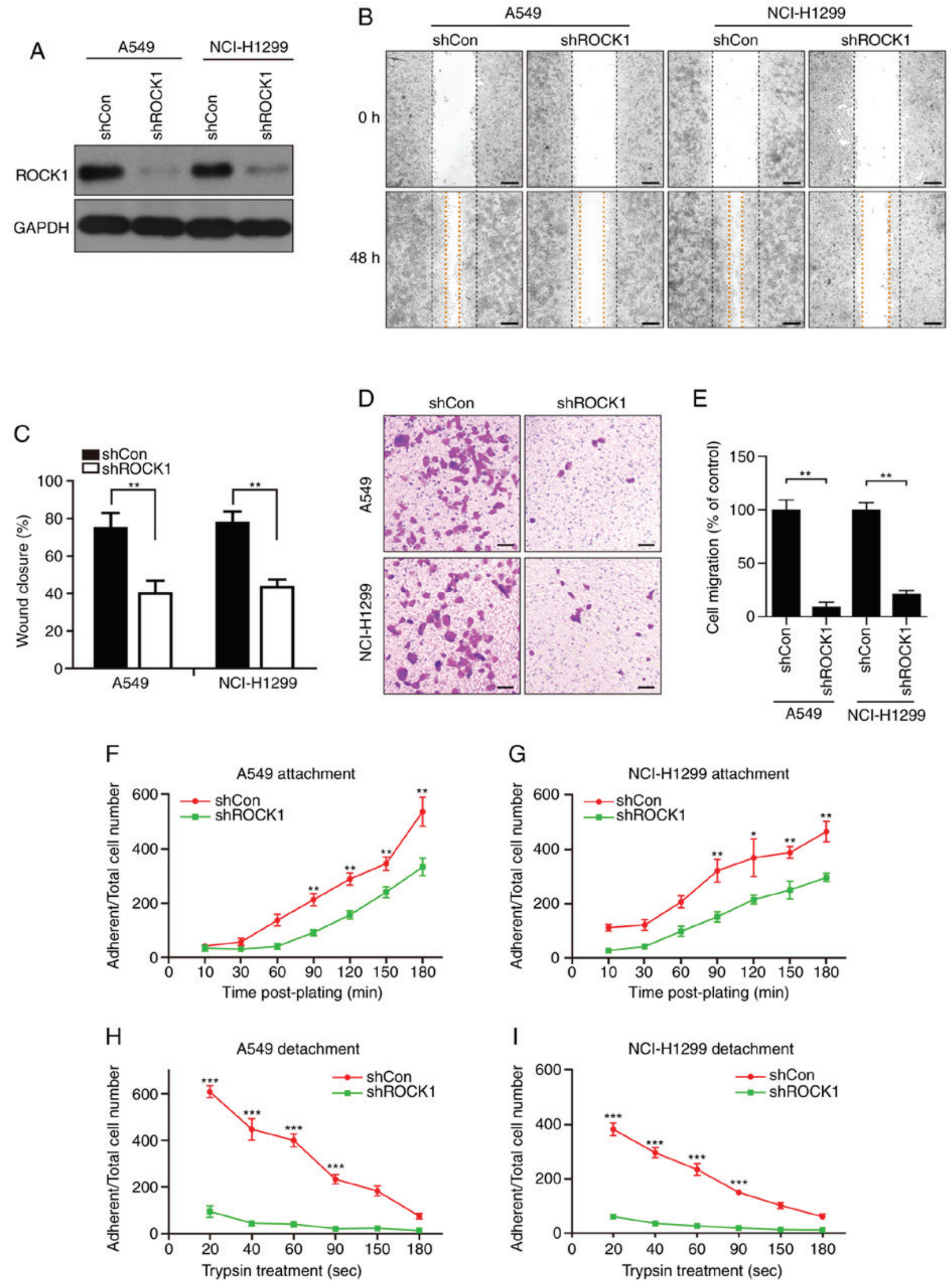

Figure 2. ROCK1 promotes the migration and invasion of NSCLC A549 and NCI-H1299 cells. (A) ROCK1 knockdown efficiency of the shRNA was measured by western blotting. (B and C) The role of ROCK1 in A549 and NCI-H1299 cell migration was evaluated by the wound healing assay. The wound closure distance was measured in 3 randomly selected fields. Scale bars: $200 \mu \mathrm{m}$. (D and E) The Transwell assay was employed to evaluate the effects of shROCK1 on cell invasion; the number of invading cells was counted from three independent experiments. Scale bars: $200 \mu \mathrm{m}$. (F) A549 and (G) NCI-H1299 cells were seeded in fibronectin-coated plates and cultured for 10-180 min; the adherent cells were trypsinized and counted at each time point. (H and I) Cells were cultured in 12-well plates $\left(1 \times 10^{3}\right.$ cells per well) for $24 \mathrm{~h}$, then trypsinized with a diluted trypsin solution (trypsin:PBS, 1:19) for different time intervals (20-180 sec). The remaining adherent cells were digested and counted. Each experiment was repeated three times. All data are presented as the mean \pm standard deviation $\left({ }^{*} \mathrm{P}<0.05,{ }^{* *} \mathrm{P}<0.01,{ }^{* * *} \mathrm{P}<0.001\right)$. ROCK1, Rho-associated protein kinase 1; NSCLC, non-small-cell lung cancer. 

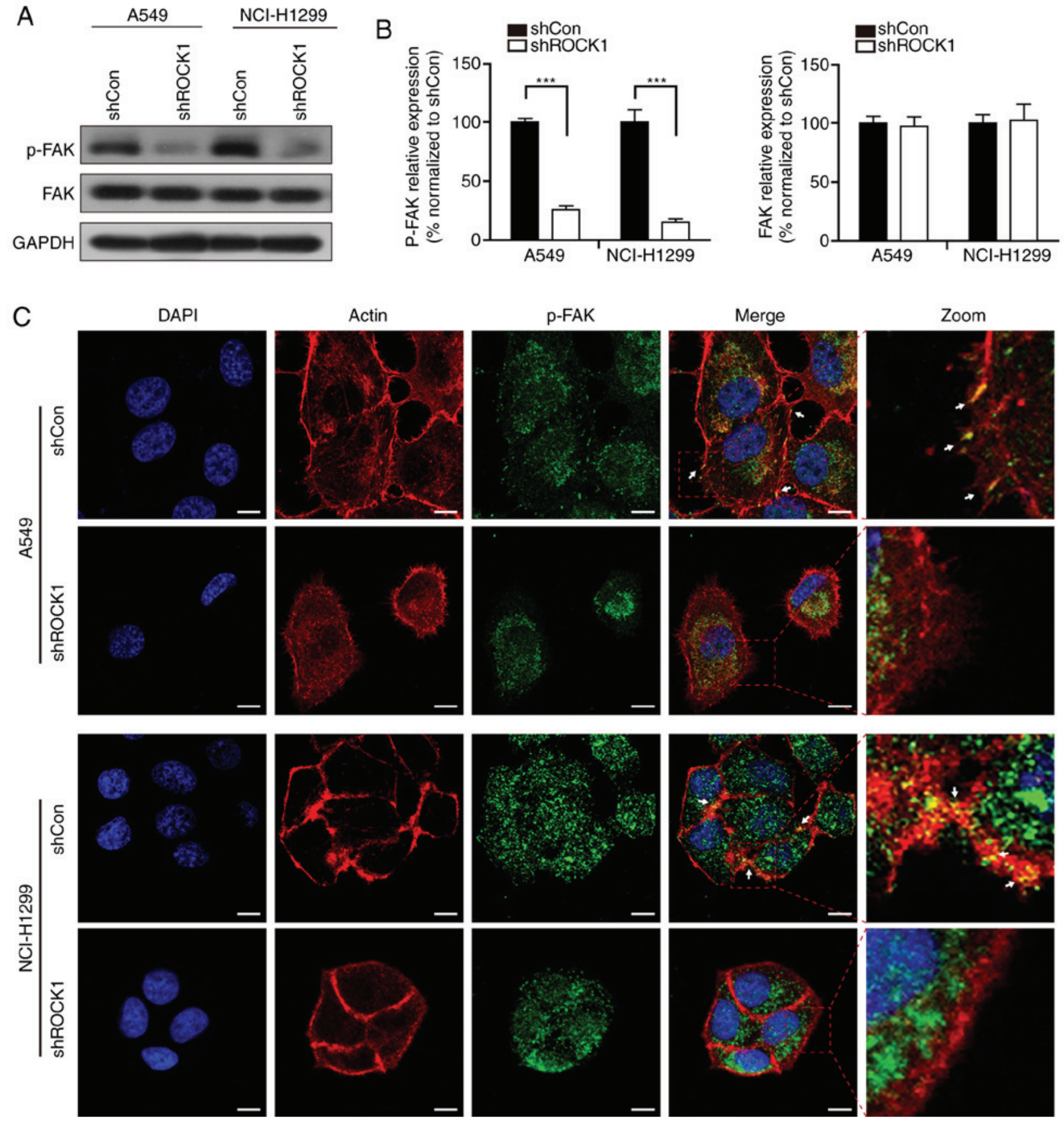

Figure 3. ROCK1 regulates the phosphorylation of FAK in NSCLC cells. (A and B) The expression levels of FAK and p-FAK were detected by western blotting after ROCK1 knockdown. The relative protein expression was analyzed by Quantity One software $\left({ }^{* * *} \mathrm{P}<0.001\right)$. The results represent three independent experiments. (C) Cells were seeded on coverslips and immunostained with actin (red), p-FAK (green) and DAPI (blue). The arrows indicate the lamellipodia (colocalization of p-FAK with actin) on the cell membrane. Scale bars: $10 \mu \mathrm{m}$. ROCK1, Rho-associated protein kinase 1; NSCLC, non-small-cell lung cancer; FAK, focal adhesion kinase.

underlying NSCLC metastasis. The present study provided evidence that ROCK1 is involved in NSCLC cell migration and invasion. It was demonstrated that ROCK1 knockdown reduced the ability of migration and invasion in A549 and NCI-H1299 cells. It was also observed that ROCK1 induced the activation/phosphorylation of the adhesion-related protein FAK in NSCLC. To better characterize this gene, we further investigated the possible mechanism of ROCK1-related cell migration and invasion in A549 and NCI-H1299 cells.
FAK, also referred to as PTK2 protein tyrosine 2, is encoded by the PTK2 gene in humans (38). FAK is an important tyrosine kinase that plays key roles in cell adhesion, cell cycle progression, cell motility and migration $(39,40)$. Increased expression of FAK has been observed in several human tumors, and incremental expression of FAK is correlated with poor prognosis (41-43). Cell adhesion and migration are regulated by the activation/phosphorylation of FAK $(32,44)$. In addition, the activation/phosphorylation of FAK was reported to be controlled by the RhoA/ROCK1/MLC signaling pathway in 
A
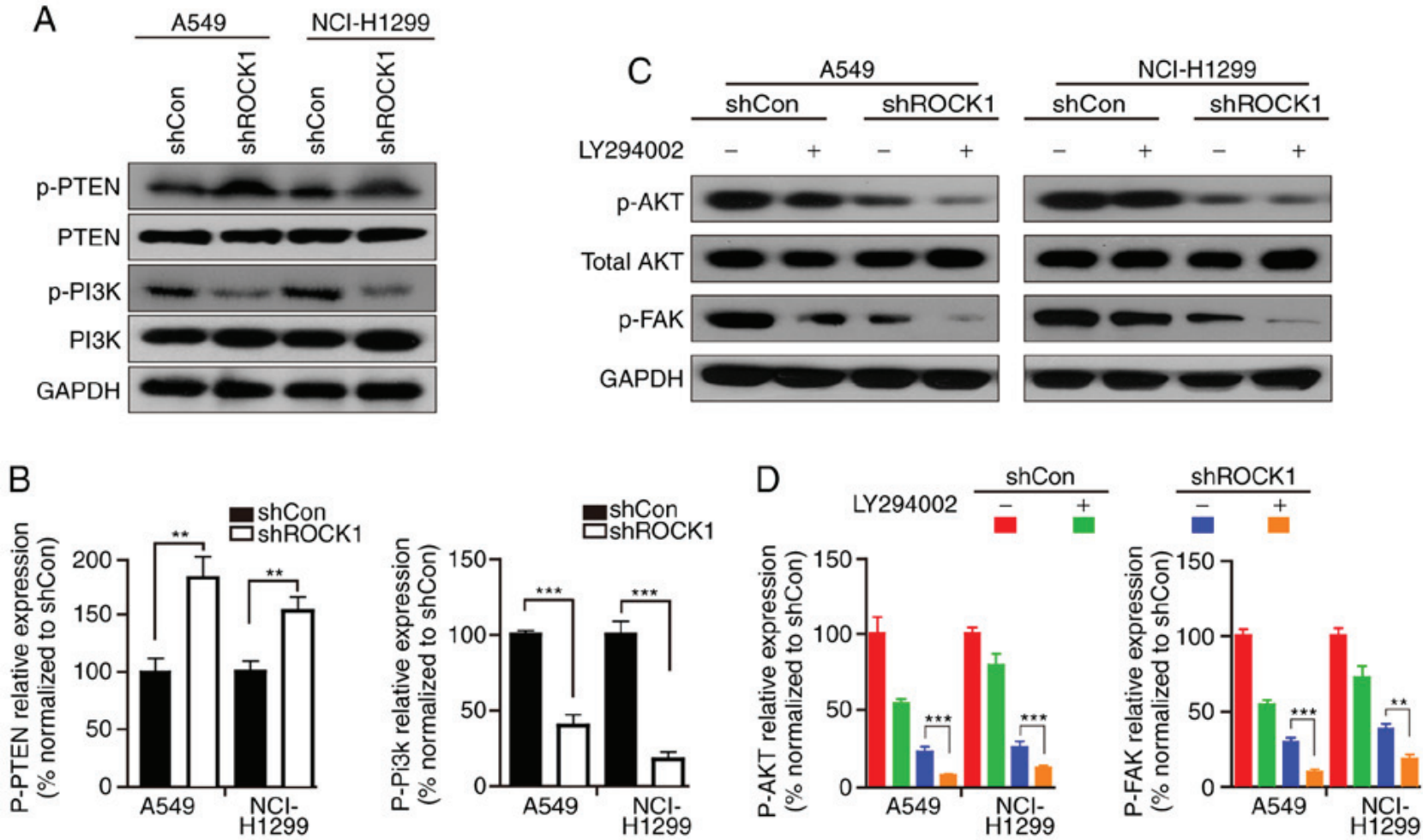

E A549

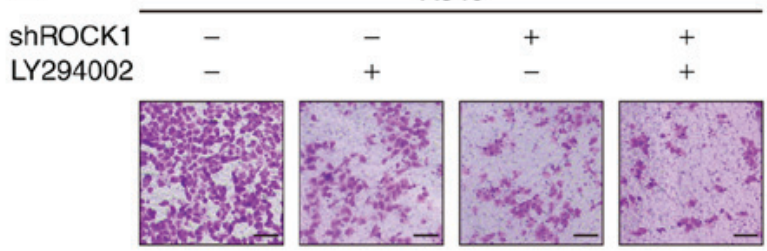

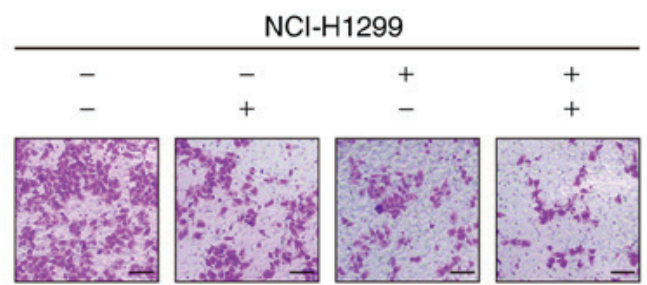

$\mathrm{F}$ A549
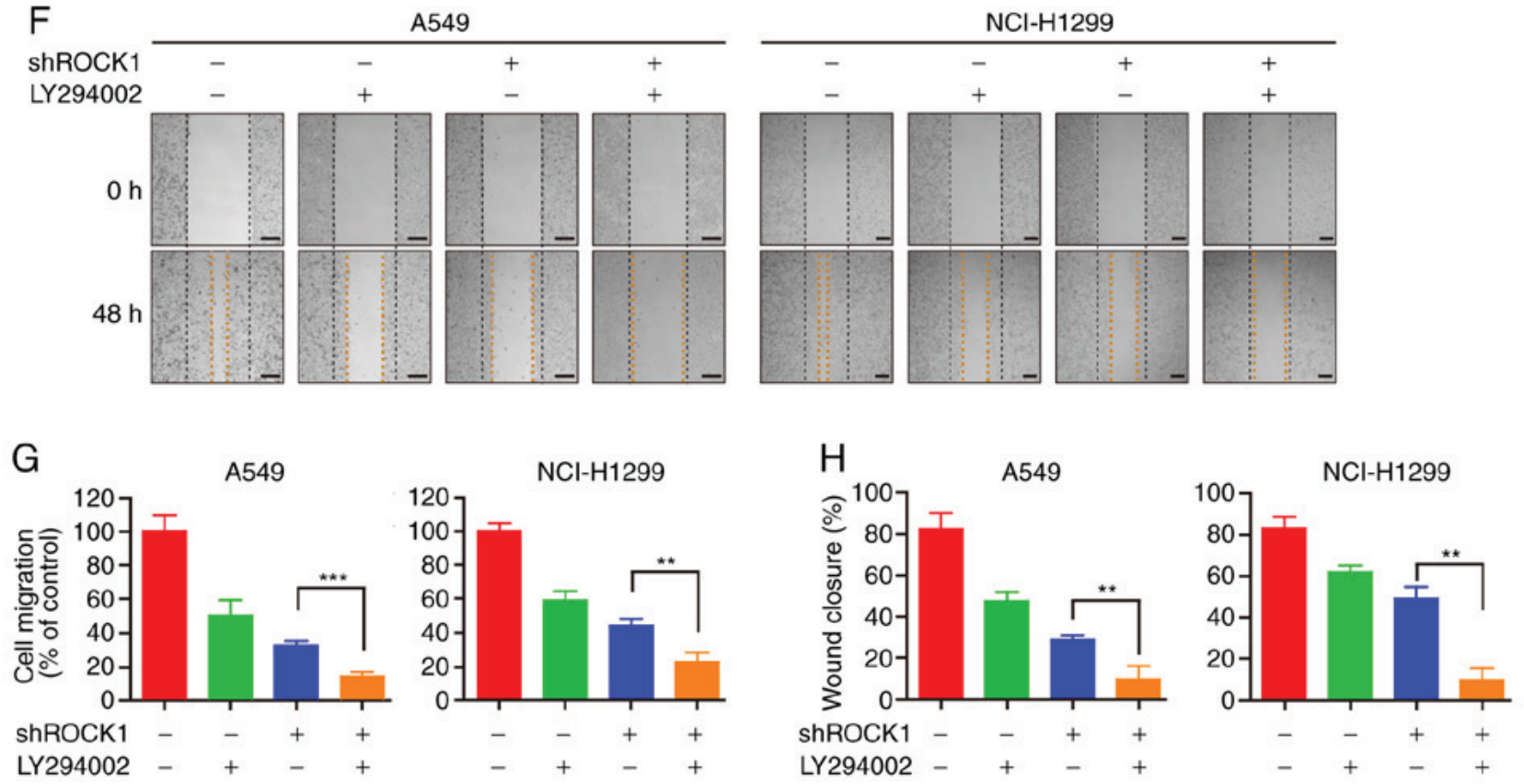

Figure 4. Effects of ROCK1 on the PI3K signaling pathway. (A) Following transfection with ROCK1 shRNA, the expression levels of p-PTEN/PTEN and p-PI3K/PI3K were analyzed by western blotting in A549 and NCI-H1299 cells. (B) The ratio of these proteins was analyzed by Quantity One software $\left({ }^{* *} \mathrm{P}<0.01,{ }^{* * *} \mathrm{P}<0.001\right)$. The results represent three independent experiments. (C) LY294002 was added to A549 and NCI-H1299 cells, and the expression of p-AKT/AKT and p-FAK was detected by western blotting. (D) The ratio of these protein expressions was analyzed by Quantity One software ${ }^{* *} \mathrm{P}<0.01$, $\left.{ }^{* * *} \mathrm{P}<0.001\right)$. The results represent three independent experiments. (E and G) Invasion of A549 and NCI-H1299 cells was measured by the Transwell assay, and the invading cells were counted in three independent fields $\left({ }^{* *} \mathrm{P}<0.01\right)$. (F and $\left.\mathrm{H}\right)$ Migration was measured by the cell monolayer scratching assay, and wound closure was measured in randomly selected fields ( $\left.{ }^{* *} \mathrm{P}<0.01\right)$. Scale bars: $200 \mu \mathrm{m}$. ROCK1, Rho-associated protein kinase 1 ; FAK, focal adhesion kinase; PI3K, phosphoinositide 3 kinase; PTEN, phosphatase and tensin homolog. 

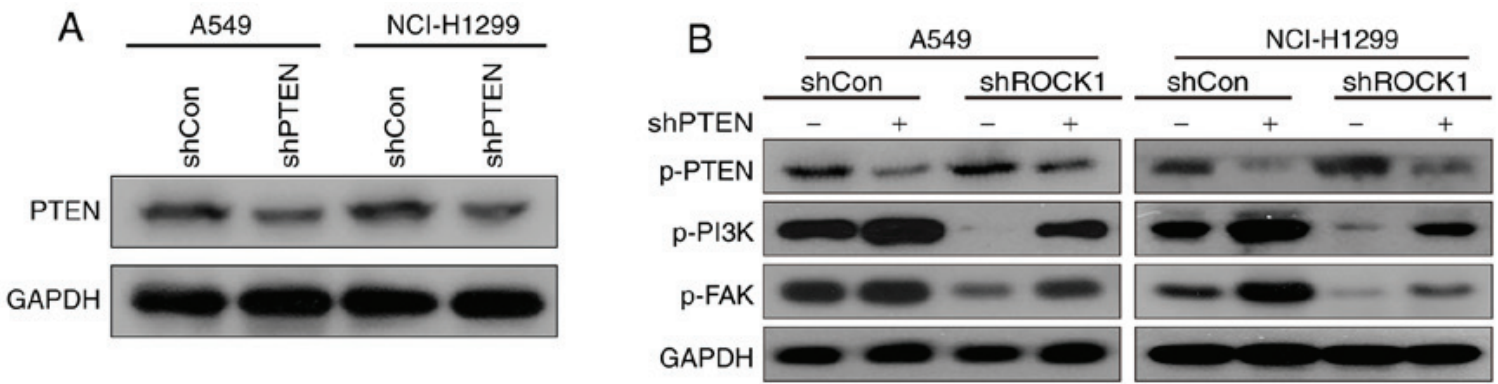

C

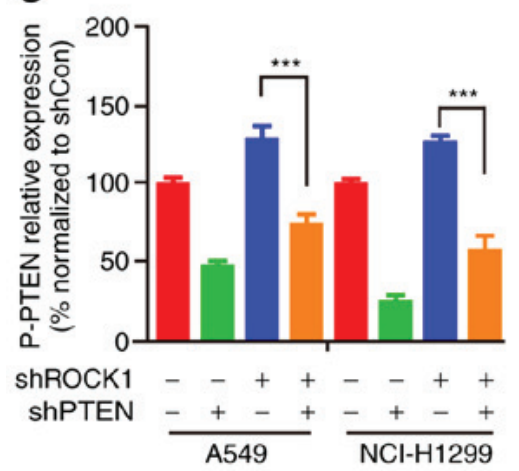

D

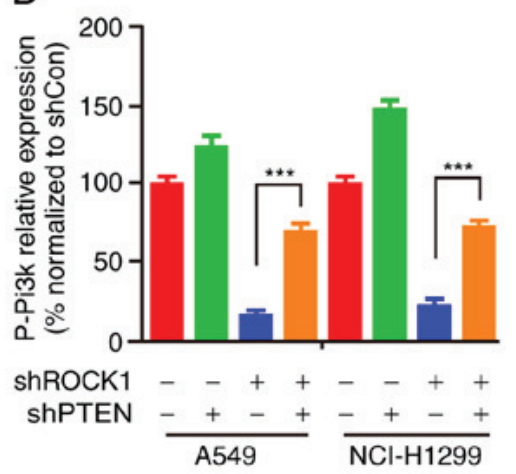

$\mathrm{E}$

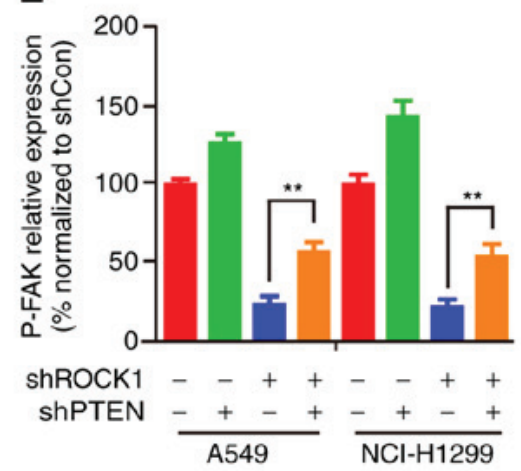

$\mathrm{F}$ ShROCK1
ShPTEN
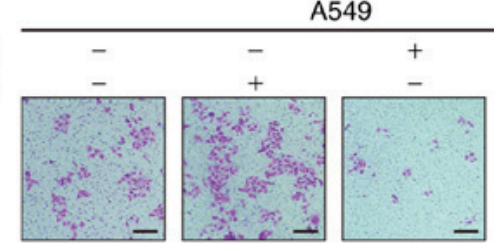

49
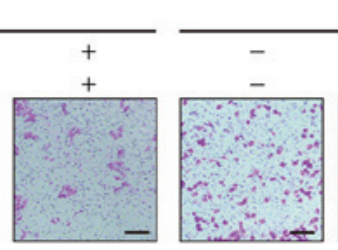

$\mathrm{NCl}-\mathrm{H} 1299$

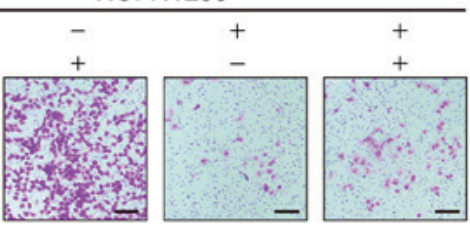

$\mathrm{H}$
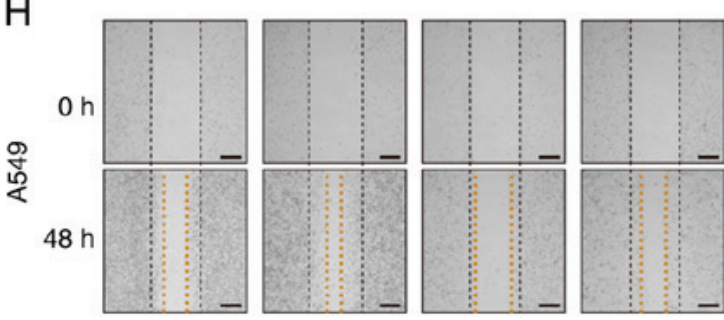

G
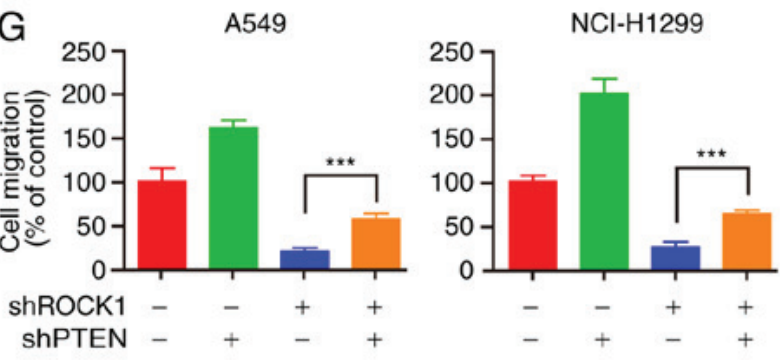

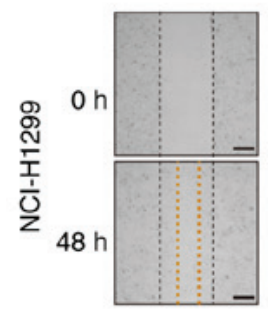

shROCK1

ShPTEN
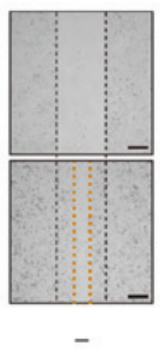

$+$

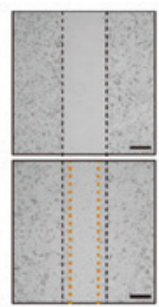

$+$

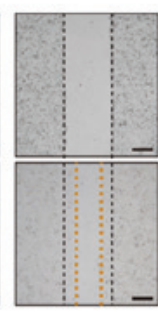

$+$

$+$
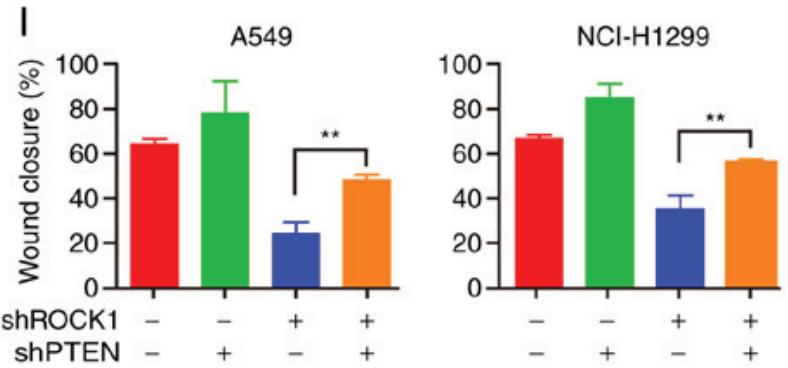

Figure 5. PTEN is an important intermediate regulator in ROCK1-mediated PI3K/FAK pathway activation. (A) The PTEN knockdown efficiency of the shRNA was measured by western blotting. (B) Stable cell lines (shROCK1, shPTEN and shROCK1 + shPTEN) were prepared and analyzed for the expression of p-PTEN, p-PI3K and p-FAK by western blotting. The relative expression of (C) p-PTEN, (D) p-PI3K and (E) p-FAK was analyzed by Quantity One software $\left({ }^{* *} \mathrm{P}<0.01,{ }^{* * *} \mathrm{P}<0.001\right)$. The results represent three independent experiments. (F-G) Invasion of A549 and NCI-H1299 cells was measured by the Transwell assay, and the invading cells were analyzed in three independent experiments $\left.{ }^{* * *} \mathrm{P}<0.001\right)$. (H-I) Furthermore, migration was measured by the cell monolayer scratching assay, and the wound closure was measured at three randomly selected fields ( $\left.{ }^{* *} \mathrm{P}<0.01\right)$. PTEN, phosphatase and tensin homolog; PI $3 \mathrm{~K}$, phosphoinositide 3 kinase; ROCK1, Rho-associated protein kinase 1; FAK, focal adhesion kinase.

breast cancer cells (45). Consistently with these studies, the findings of the present demonstrated that the phosphorylation of
FAK is necessary for ROCK1-mediated cell adhesion based on the following data: First, knockdown of ROCK1 significantly 


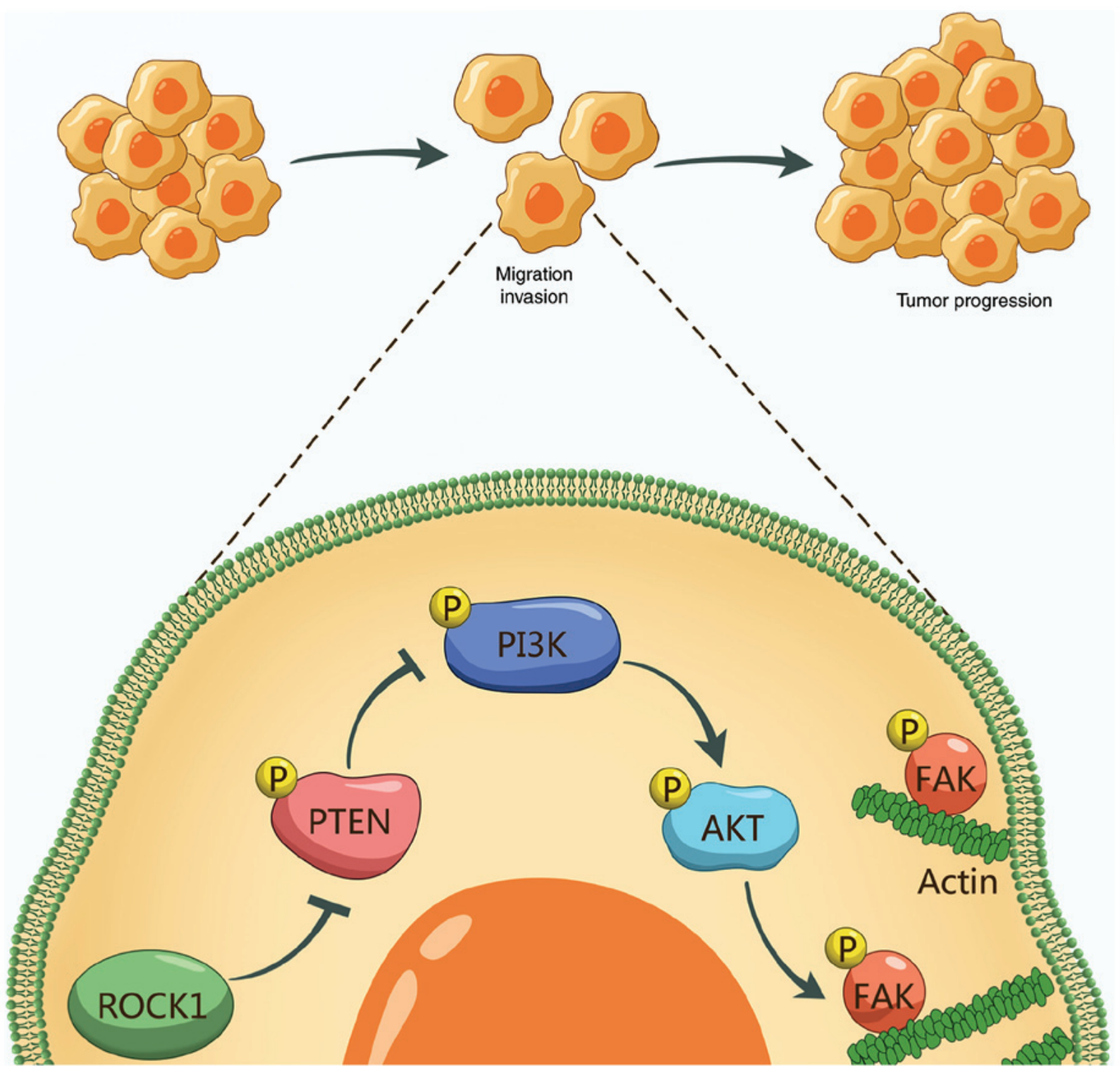

Figure 6. Mechanism of ROCK1 promoting tumor cell migration, invasion and progression in NSCLC. ROCK1 reduces the activation/phosphorylation of PTEN and then phosphorylates PI3K/AKT, resulting in FAK phosphorylation and leading to accelerated cell migration/invasion and promotion of NSCLC progression. ROCK1, Rho-associated protein kinase 1; NSCLC, non-small-cell lung cancer; PTEN, phosphatase and tensin homolog; PI3K, phosphoinositide 3 kinase; FAK, focal adhesion kinase.

decreased the adhesion ability of A549 and NCI-H1299 cells. Second, knockdown of ROCK1 significantly decreased the expression of activated/phosphorylated FAK. Third, knockdown of ROCK1 also decreased lamellipodia formation, with a decrease in colocalization of p-FAK and actin on the surface of the cell membrane compared with shCon cells. Therefore, these data suggest that ROCK1-mediated cell adhesion is dependent on FAK activation/phosphorylation.

These results also provide more detailed information on the molecular mechanisms through which ROCK1 induces migration and invasion in NSCLC cells through the PTEN/PI3K/FAK pathway. ROCK is involved in a wide range of basic cellular functions, such as apoptosis, contraction, proliferation, adhesion and migration (46). It was recently demonstrated that ROCK1 is highly expressed in glioblastoma (9), melanoma (10), osteosarcoma (11) and hepatocellular carcinoma (12). Moreover, ROCK1 may be of value as a potential target for cancer therapy (47). Furthermore, several studies reported that PTEN, a well-known tumor suppressor, is the core downstream substrate of ROCK1, which is involved in regulating cancer cells $(25,48,49)$. In addition, the PI3K/AKT pathway was reported to be downstream of PTEN, which is involved in the regulation of cell migration and invasion $(50,51)$. Based on these results, it may be hypothesized that the PTEN/PI3K/AKT signaling pathway acts downstream of ROCK1, ultimately leading to the activation/phosphorylation of FAK and, subsequently, the promotion of cell adhesion, migration and invasion. Knockdown of ROCK1 was found to induce PTEN activation and PI3K/AKT inactivation. Pretreatment with a PI3K inhibitor, LY294002, enhanced the ROCK1 knockdown-mediated inactivation of AKT, the dephosphorylation of FAK, and the inhibition of cell migration and invasion. In addition, further knockdown of PTEN attenuated the ROCK1 knockdown-mediated activation of 
PTEN, inactivation of PI3K, and dephosphorylation of FAK, as well as inhibition of cell migration and invasion. These results suggest that ROCK1-mediated NSCLC cell adhesion, migration and invasion occur through inactivation of PTEN and activation of the PI3K/FAK pathway.

In conclusion, the results of the present study demonstrated that ROCK1 is highly expressed in NSCLC cells and tissues, and is associated with poor survival. In addition, ROCK1 plays an important role in the occurrence and development of NSCLC through regulating cancer cell migration and invasion. In summary, these results suggest a hierarchy of events in ROCK1-induced cell migration and invasion, in which ROCK1 reduces the activation/phosphorylation of PTEN and then phosphorylates PI3K/AKT, resulting in FAK phosphorylation and leading to accelerated cell migration/invasion, thereby promoting NSCLC progression (Fig. 6). The present study may enable a better understanding of the role of ROCK1 in NSCLC tumorigenesis and cancer aggressiveness, and suggests that ROCK1 may be a potential therapeutic target for NSCLC treatment.

\section{Acknowledgements}

Not applicable.

\section{Funding}

The present study was supported by grants from the National Natural Science Foundation of China (no. 81801273), the Chongqing Natural Science Foundation Program (no. cstc 2018jcyAX0183), the Youth Talent Project of Army Medical University (no. 2017R023) and the Clinical Research Project of Xinqiao Hospital, Army Medical University (no. 2016YLC12).

\section{Availability of data and materials}

All the datasets generated and analyzed in the present study are included in this published article.

\section{Authors' contributions}

CPH, HYZ and GBL conceived and designed the study and wrote the manuscript. $\mathrm{CPH}$ and $\mathrm{HYZ}$ performed the experiments. YLL and JBH collected the data. WYL, QZ and QT analyzed the data. $\mathrm{CPH}$ and FFS interpreted the data. GBL and RZ reviewed the manuscript. All authors have read and approved the final version of this manuscript for publication.

\section{Ethics approval and consent to participate}

Not applicable.

\section{Patient consent for publication}

Not applicable.

\section{Competing interests}

The authors declare that they have no competing interests.

\section{References}

1. Chen W, Zheng R, Baade PD, Zhang S, Zeng H, Bray F, Jemal A, $\mathrm{Yu}$ XQ and He J: Cancer statistics in China, 2015. CA Cancer J Clin 66: 115-132, 2016.

2. Siegel RL, Miller KD and Jemal A: Cancer statistics, 2018. CA Cancer J Clin 68: 7-30, 2018.

3. She K, Yan H, Huang J, Zhou H and He J: miR-193b availability is antagonized by LncRNA-SNHG7 for FAIM2-induced tumour progression in non-small cell lung cancer. Cell Prolif: 51, 2018, doi: $10.1111 /$ cpr.12406.

4. Yang J, Zhao H, Xin Y and Fan L: MicroRNA-198 inhibits proliferation and induces apoptosis of lung cancer cells via targeting FGFR1. J Cell Biochem 115: 987-995, 2014.

5. Kohler J: Second-line treatment of NSCLC-the Pan-ErbB inhibitor afatinib in times of shifting paradigms. Front Med (Lausanne) 4: 9, 2017.

6. Patel RA, Liu Y, Wang B, Li R and Sebti SM: Identification of novel ROCK inhibitors with anti-migratory and anti-invasive activities. Oncogene 33: 550-555, 2014.

7. Vigil D, Kim TY, Plachco A, Garton AJ, Castaldo L, Pachter JA, Dong H, Chen X, Tokar B, Campbell SL and Der CJ: ROCK1 and ROCK2 are required for non-small cell lung cancer anchorage-independent growth and invasion. Cancer Res 72: 5338-5347, 2012.

8. Rath $\mathrm{N}$ and Olson MF: Rho-associated kinases in tumorigenesis: Re-considering ROCK inhibition for cancer therapy. EMBO Rep 13: 900-908, 2012.

9. Xu S, Guo X, Gao X, Xue H, Zhang J, Guo X, Qiu W, Zhang P and Li G: Macrophage migration inhibitory factor enhances autophagy by regulating ROCK1 activity and contributes to the escape of dendritic cell surveillance in glioblastoma. Int $\mathrm{J}$ Oncol 49: 2105-2115, 2016.

10. Huang GX, Wang Y, Su J, Zhou P, Li B, Yin LJ and Lu J: Up-regulation of Rho-associated kinase $1 / 2$ by glucocorticoids promotes migration, invasion and metastasis of melanoma. Cancer Lett 410: 1-11, 2017.

11. Wang Z, Wang Z, Liu J and Yang H: Long non-coding RNA SNHG5 sponges miR-26a to promote the tumorigenesis of osteosarcoma by targeting ROCK1. Biomed Pharmacother 107: 598-605, 2018.

12. Zhan Y, Zheng N, Teng F, Bao L, Liu F, Zhang M, Guo M, Guo W, Ding G and Wang Q: MiR-199a/b-5p inhibits hepatocellular carcinoma progression by post-transcriptionally suppressing ROCK1. Oncotarget 8: 67169-67180, 2017.

13. Croft DR, Sahai E, Mavria G, Li S, Tsai J, Lee WM, Marshall CJ and Olson MF: Conditional ROCK activation in vivo induces tumor cell dissemination and angiogenesis. Cancer Res 64: 8994-9001, 2004.

14. Peng Y, Chen Z, Chen Y, Li S, Jiang Y, Yang H, Wu C, You F, Zheng $\mathrm{C}$, Zhu J, et al: ROCK isoforms differentially modulate cancer cell motility by mechanosensing the substrate stiffness. Acta Biomater 88: 86-101, 2019.

15. Zhao J and Guan JL: Signal transduction by focal adhesion kinase in cancer. Cancer Metastasis Rev 28: 35-49, 2009.

16. Liu W, Liang Y, Chan Q, Jiang L and Dong J: CX3CL1 promotes lung cancer cell migration and invasion via the Src/focal adhesion kinase signaling pathway. Oncol Rep 41: 1911-1917, 2019.

17. Gates RE, King LE Jr, Hanks SK and Nanney LB: Potential role for focal adhesion kinase in migrating and proliferating keratinocytes near epidermal wounds and in culture. Cell Growth Differ 5: 891-899, 1994

18. Azab AK, Azab F, Blotta S, Pitsillides CM, Thompson B Runnels JM, Roccaro AM, Ngo HT, Melhem MR, Sacco A, et al: RhoA and Racl GTPases play major and differential roles in stromal cell-derived factor-1-induced cell adhesion and chemotaxis in multiple myeloma. Blood 114: 619-629, 2009.

19. Jaraiz-Rodriguez M, Tabernero MD, Gonzalez-Tablas M, Otero A, Orfao A, Medina JM and Tabernero A: A short region of Connexin43 reduces human glioma stem cell migration, invasion, and survival through Src, PTEN, and FAK. Stem Cell Reports 9: 451-463, 2017.

20. Zhang LL, Liu J, Lei S, Zhang J, Zhou W and Yu HG: PTEN inhibits the invasion and metastasis of gastric cancer via downregulation of FAK expression. Cell Signal 26: 1011-1020, 2014.

21. Tamura M, Gu J, Matsumoto K, Aota S, Parsons R and Yamada KM: Inhibition of cell migration, spreading, and focal adhesions by tumor suppressor PTEN. Science 280: 1614-1617, 1998. 
22. Julian L and Olson MF: Rho-associated coiled-coil containing kinases (ROCK): Structure, regulation, and functions. Small GTPases 5: e29846, 2014.

23. Guan R, Xu X, Chen M, Hu H, Ge H, Wen S, Zhou S and Pi R: Advances in the studies of roles of Rho/Rho-kinase in diseases and the development of its inhibitors. Eur J Med Chem 70: 613-622, 2013.

24. Fragoso R and Barata JT: Kinases, tails and more: Regulation of PTEN function by phosphorylation. Methods 77-78: 75-81, 2015.

25. Malemud CJ: The PI3K/Akt/PTEN/mTOR pathway: A fruitful target for inducing cell death in rheumatoid arthritis? Future Med Chem 7: 1137-1147, 2015

26. Zhang R, Li G, Zhang Q, Tang Q, Huang J, Hu C, Liu Y, Wang Q, Liu W, Gao N and Zhou S: Hirsutine induces mPTP-dependent apoptosis through ROCK1/PTEN/PI3K/GSK3 $\beta$ pathway in human lung cancer cells. Cell Death Dis 9: 598, 2018.

27. Rami-Porta R, Asamura H, Travis WD and Rusch VW: Lung cancer-major changes in the American Joint Committee on Cancer eighth edition cancer staging manual. CA Cancer J Clin 67: 138-155, 2017.

28. Remmele W and Stegner HE: Recommendation for uniform definition of an immunoreactive score (IRS) for immunohistochemical estrogen receptor detection (ER-ICA) in breast cancer tissue. Pathologe 8: 138-140, 1987 (In German).

29. Shi H, Chen S, Jin H, Xu C, Dong G, Zhao Q, Wang W, Zhang H, Lin W, Zhang J, et al: Downregulation of MSP58 inhibits growth of human colorectal cancer cells via regulation of the cyclin D1-cyclin-dependent kinase 4-p21 pathway. Cancer Sci 100: 1585-1590, 2009.

30. Wang GH, Yao L, Xu HW, Tang WT, Fu JH, Hu XF, Cui L and Xu XM: Identification of MXRA5 as a novel biomarker in colorectal cancer. Oncol Lett 5: 544-548, 2013.

31. Toro-Tapia G, Villaseca S, Beyer A, Roycroft A, Marcellini S, Mayor R and Torrejón M: The Ric-8A/Ga13/FAK signaling cascade controls focal adhesion formation during neural crest cell migration in Xenopus. Development 145: pii: dev164269, 2018.

32. Liu C, Li Y, Xing Y, Cao B, Yang F, Yang T, Ai Z, Wei Y and Jiang J: The interaction between cancer stem cell marker CD133 and Src protein promotes focal adhesion kinase (FAK) phosphorylation and cell migration. J Biol Chem 291: 15540-15550, 2016.

33. Matsuda S, Kawamoto K, Miyamoto K, Tsuji A and Yuasa K: PCTK3/CDK18 regulates cell migration and adhesion by negatively modulating FAK activity. Sci Rep 7: 45545, 2017.

34. Zhang J, Li L, Peng Y, Chen Y, Lv X, Li S, Qin X, Yang H, Wu C and Liu Y: Surface chemistry induces mitochondria-mediated apoptosis of breast cancer cells via PTEN/PI3K/AKT signaling pathway. Biochim Biophys Acta Mol Cell Res 1865: 172-185, 2018.

35. Alfieri R, Giovannetti E, Bonelli M and Cavazzoni A: New treatment opportunities in phosphatase and tensin homolog (PTEN)-deficient tumors: Focus on PTEN/Focal adhesion kinase pathway. Front Oncol 7: 170, 2017.

36. Vemula S, Shi J, Hanneman P, Wei L and Kapur R: ROCK1 functions as a suppressor of inflammatory cell migration by regulating PTEN phosphorylation and stability. Blood 115 $1785-1796,2010$

37. Li GB, Cheng Q, Liu L, Zhou T, Shan CY, Hu XY, Zhou J, Liu EH, Li P and Gao N: Mitochondrial translocation of cofilin is required for allyl isothiocyanate-mediated cell death via ROCK1/PTEN/PI3K signaling pathway. Cell Commun Signal 11: 50, 2013.
38. André E and Becker-André M: Expression of an N-terminally truncated form of human focal adhesion kinase in brain. Biochem Biophys Res Commun 190: 140-147, 1993.

39. Zhang J and Hochwald SN: The role of FAK in tumor metabolism and therapy. Pharmacol Ther 142: 154-163, 2014.

40. Schaller MD: Biochemical signals and biological responses elicited by the focal adhesion kinase. Biochim Biophys Acta 1540: $1-21,2001$

41. Siesser PM and Hanks SK: The signaling and biological implications of FAK overexpression in cancer. Clin Cancer Res 12: 3233-3237, 2006

42. Ucar DA and Hochwald SN: FAK and interacting proteins as therapeutic targets in pancreatic cancer. Anticancer Agents Med Chem 10: 742-746, 2010.

43. Sulzmaier FJ, Jean C and Schlaepfer DD: FAK in cancer: Mechanistic findings and clinical applications. Nat Rev Cancer 14: 598-610, 2014.

44. Roycroft A, Szabó A, Bahm I, Daly L, Charras G, Parsons M and Mayor R: Redistribution of adhesive forces through Src/FAK drives contact inhibition of locomotion in neural crest. Dev Cell 45: 565-579.e3, 2018

45. Gilkes DM, Xiang L, Lee SJ, Chaturvedi P, Hubbi ME, Wirtz D and Semenza GL: Hypoxia-inducible factors mediate coordinated RhoA-ROCK1 expression and signaling in breast cancer cells. Proc Natl Acad Sci USA 111: E384-E393, 2014.

46. Amin E, Dubey BN, Zhang SC, Gremer L, Dvorsky R, Moll JM, Taha MS, Nagel-Steger L, Piekorz RP, Somlyo AV and Ahmadian MR: Rho-kinase: Regulation, (dys)function, and inhibition. Biol Chem 394: 1399-1410, 2013.

47. Wermke M, Camgoz A, Paszkowski-Rogacz M, Thieme S, von Bonin M, Dahl A, Platzbecker U, Theis M, Ehninger G, Brenner S, et al: RNAi profiling of primary human AML cells identifies ROCK1 as a therapeutic target and nominates fasudil as an antileukemic drug. Blood 125: 3760-3768, 2015.

48. Zhu L, Wang X, Wang T, Zhu W and Zhou X: miR-494-3p promotes the progression of endometrial cancer by regulating the PTEN/PI3K/AKT pathway. Mol Med Rep 19: 581-588, 2019.

49. Wu YR, Qi HJ, Deng DF, Luo YY and Yang SL: MicroRNA-21 promotes cell proliferation, migration, and resistance to apoptosis through PTEN/PI3K/AKT signaling pathway in esophageal cancer. Tumour Biol 37: 12061-12070, 2016.

50. Fu Q, Huang Y, Ge C, Li Z, Tian H, Li Q, Li H, Li R, Tao X, Xue Y, et al: SHIP1 inhibits cell growth, migration, and invasion in nonsmall cell lung cancer through the PI3K/AKT pathway. Oncol Rep 41: 2337-2350, 2019.

51. Jiang W, Cheng Y, Zhao N, Li L, Shi Y, Zong A and Wang F: Sulfated polysaccharide of Sepiella Maindroni ink inhibits the migration, invasion and matrix metalloproteinase- 2 expression through suppressing EGFR-mediated p38/MAPK and $\mathrm{PI} 3 \mathrm{~K} / \mathrm{Akt} / \mathrm{mTOR}$ signaling pathways in SKOV-3 cells. Int J Biol Macromol 107: 349-362, 2018.

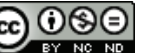

This work is licensed under a Creative Commons Attribution-NonCommercial-NoDerivatives 4.0 International (CC BY-NC-ND 4.0) License. 